\title{
An alternative approach to the tribological analysis of Si-doped DLC coatings deposited with different bias voltages using Raman spectroscopy mapping
}

\author{
Bruno J. Rodriguez ${ }^{1,2}$ (D) Parnia Navabpour ${ }^{3} \cdot$ Daniela Proprentner $^{1} \cdot$ Marc Walker $^{4} \cdot$ Hailin Sun $^{3} \cdot$ Tara L. Schiller $^{1}$
}

Received: 2 June 2021 / Accepted: 3 July 2021 / Published online: 10 August 2021

(c) The Author(s) 2021

\begin{abstract}
A series of diamond-like carbon (DLC) coatings were deposited with increasing bias voltage using magnetron sputtering techniques. Structural changes were observed in the $\mathrm{sp}^{2}$-configuration across the films which were accompanied by a slight increase in the $\mathrm{sp}^{3}$ fraction. With an increasing bias voltage, the thermal stability of the coatings increased from 300 to $450{ }^{\circ} \mathrm{C}$. Oxygen diffusion was observed through the coating as a result of the high-temperature annealing and found to slow down with increasing bias voltage. Coefficients of friction (COF) remained stable with temperature for the individual coatings, with the softer films reporting the lowest COF. Our approach employed Raman spectroscopy to map the wear tracks at different temperatures, providing a deeper understanding of the coating performance and suggested maximum flash temperatures endured during testing.
\end{abstract}

Keywords Diamond-like $\cdot$ High-temperature $\cdot$ Raman $\cdot$ X-ray photoelectron $\cdot$ Tribology

\section{Introduction}

Diamond-like carbon (DLC) coatings have been widely researched during the past decade. These coatings are currently used for automotive, aerospace, biomedical, or manufacturing purposes, amongst others [1-4]. The wide range of applications of these films arises from their remarkable properties, such as low friction and high wear resistance, chemical inertness, nano-smoothness, or even anti-bacterial properties [5, 6].

These coatings have also some limitations complicating their wider application, such as the low thermal stability, dependence on the sliding environment, or the adhesion strength [7-10]. As the environmental temperature is

Bruno J. Rodriguez

b.rodriguez@warwick.ac.uk

WMG, University of, Warwick, Coventry CV4 7AL, UK

2 Diamond Science and Technology CDT, University of Warwick, Coventry CV4 7AL, UK

3 Teer Coatings Ltd., West Stone House, Berry Hill Industrial Estate, Droitwich WR9 9AS, UK

4 Department of Physics, University of Warwick, Coventry CV4 7AL, UK increased, these coatings undergo a transformation in their $\mathrm{sp}^{2}$ configuration, where the existing olefinic bonds become aromatic $[11,12]$. Simultaneously, a reduction in the hardness and $\mathrm{sp}^{3}$ fraction has also been reported, as well as an increasing wear rate with temperature [13-16]. The sliding environment has been reported to affect greatly the surface chemistry of these films, reporting large differences in COF in dry environments and humid, as well as between those coatings deposited with hydrogenated precursors and without them [7, 17, 18].

Doping the films has increasingly appeared as an opportunity to overcome the existing limitations and even provide new properties. Silicon doping, as studied in this work, has been reported to increase the thermal stability of the films, while having positive effects on the tribological properties due to the formation of silicon-oxides on the surface of the films [19-21]. Although the mechanical properties have been observed to drop with silicon doping up to a defined content threshold [22], alternative dopants can be employed to reduce the compressive stress of the film or provide new properties, such as antibacterial [15, 23].

Many plasma deposition techniques rely on bias voltages applied to the substrates to infer changes in the DLC structure through the modification in the ion bombardment energy. Bias voltages have been reported to affect different

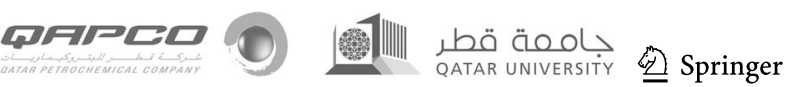


DLC properties, such as the optical properties [24], mechanical properties [25, 26], or topography [25]. There are also reports about their impact in other parameters, such as growth rate, density, compressive stress, or even hydrogen content [25-27]. Nonetheless, improvements in the aforementioned parameters are only obtained within a threshold [28], as too-high bias voltage may result in intense ion bombardments [29], causing increasing deposition temperatures and thermal spikes upon arrival to the coating, which may induce relaxation and changes in the $\mathrm{sp}^{2}$ configuration [26, $29,30]$.

In this work, we investigated the structural changes in the $\mathrm{sp}^{2}$ and $\mathrm{sp}^{3}$ configuration with increasing bias voltage, by Raman spectroscopy and $\mathrm{x}$-ray photoelectron spectroscopy (XPS). The evolution of the tribological properties with temperature for each of the studied films was examined, as well as their increased thermal stability. The effect of the bias voltage on the oxygen diffusion with increasing temperature was also studied. Finally, an alternative analysis of the $\mathrm{sp}^{2}$-configuration after tribological testing was presented, providing new insights that could help probing experimentally the maximum flash temperatures reached during contact.

\section{Experimental methodology}

Silicon-doped DLC coatings ( $1.4 \pm 0.2$ at. \%) were deposited at Teer Coatings Ltd. (Worcestershire, UK) on M42 highspeed steel specimens of $30 \mathrm{~mm}$ diameter using increasing bias voltages, following the procedures described previously $[16,31]$.

Raman spectroscopy measurements $(\lambda=532 \mathrm{~nm})$ were performed with minimised power using an inVia reflex Raman microscope (Renishaw PLC., Wotton-under-Edge, UK). The spectra were recorded for $10 \mathrm{~s}$ during 10 accumulations, from 300 to $2400 \mathrm{~cm}^{-1}$. The central area of the wear track was mapped using StreamLine ${ }^{\mathrm{TM}}$ Raman mapping. The area mapped was slightly modified as the temperature was increased due to the increasing wear track width (Y-axis), while the wear track length mapped (X-axis) was kept constant at $30 \mu \mathrm{m}$. The fitting process was automated through a custom-built script where +8000 spectra were fitted using a double Gaussian model.

Both hardness $(\mathrm{H})$ and reduced elastic modulus (E') were acquired using NanoTest Xtreme (Micromaterials Ltd., Wrexham, UK) with a diamond Berkovich indenter. The films were indented under depth-controlled conditions, ensuring that the depth remained below $200 \mathrm{~nm}$, which was below a tenth of the coating thickness to minimise the influence of surface roughness and substrate.

XPS was employed to measure the silicon content within each of the films, as well as any existing difference in terms of carbide formation, and $\mathrm{C}-\mathrm{C} \mathrm{sp}^{3}$ content induced by the different bias voltages applied. These spectra were acquired using a Kratos Axis Ultra DLD (Kratos Analytical, Manchester, UK). The work function and binding energy scale were calibrated before any experiment against the Fermi edge and $3 d_{5 / 2}$ peak of a polycrystalline $\mathrm{Ag}$ sample. Clean metallic foils were used to determine the analyser transmission function and the detection efficiency for the compositional analysis, using $\mathrm{Al} \mathrm{K} \alpha(\mathrm{hv}=1486.7 \mathrm{eV}) \mathrm{x}$-ray beams were used in both cases. The CasaXPS software was used for peak fitting with Gaussian-Lorentzian line shapes. The background of the analysed photoelectron emission band was subtracted using the Shirley method [31].

Tribological testing was carried out using a Multi-Function Tribometer MFT-5000 (Rtec Instruments, Inc., San Jose, CA, USA). A linear speed of $1 \mathrm{~cm} \mathrm{~s}^{-1}$ and a frequency of $1 \mathrm{~Hz}$ were defined for the experiments. Additionally, a load of $10 \mathrm{~N}$ was applied over $6.3 \mathrm{~mm}$ diameter $\mathrm{Al}_{2} \mathrm{O}_{3}$ balls that were used as counterparts. These experiments were carried out at different temperatures until the coating failure, which ranged from room temperature to $450{ }^{\circ} \mathrm{C}$. The temperature was calibrated to ensure that the defined values were reached on the surface of the coating, and prior to the tribological contact, both elements were annealed for $40 \mathrm{~min}$, accounting for temperature homogenization. Specific wear rates (SWR) were estimated by the relationship between both the volume of material removed and the relationship between the load applied and sliding distance. The volume removed from each of the wear tracks was estimated using an Alicona InfiniteFocus instrument (Alicona Imagine $\mathrm{GmbH}$, Graz, Austria).

\section{Results and discussion}

\subsection{Raman spectroscopy}

Raman spectroscopy was employed to analyse the bonding structure of the Si-doped DLC coatings. These coatings present two main modes under visible excitation, the $\mathrm{D}$ and $\mathrm{G}$ modes (Fig. 1) [32]. The former presents $A_{1 g}$ symmetry and covers the breathing mode of the $\mathrm{sp}^{2}$ sites in rings, while the latter, with $\mathrm{E}_{2 \mathrm{~g}}$ symmetry, covers the in-plane stretching vibrations of all pairs of $\mathrm{sp}^{2}$ atoms in either rings or chains $[12,33]$. These two are the main modes under visible excitation due to the larger cross-section of the $\mathrm{sp}^{2}$ sites [32]. The fitting process of the spectra led to the extraction of three major parameters, the $\mathrm{G}$ peak position, full-width halfmaximum of the $\mathrm{G}$ peak, FWHM $(\mathrm{G})$, and the intensity ratio between both $\mathrm{D}$ and $\mathrm{G}$ peaks, $I_{\mathrm{D}} / I_{\mathrm{G}}$ (Table 1 ).

Increasing bias voltages are often linked to more energetic ions accelerating towards the substrate, which may allow deeper penetration [26, 30]. The G-peak position 


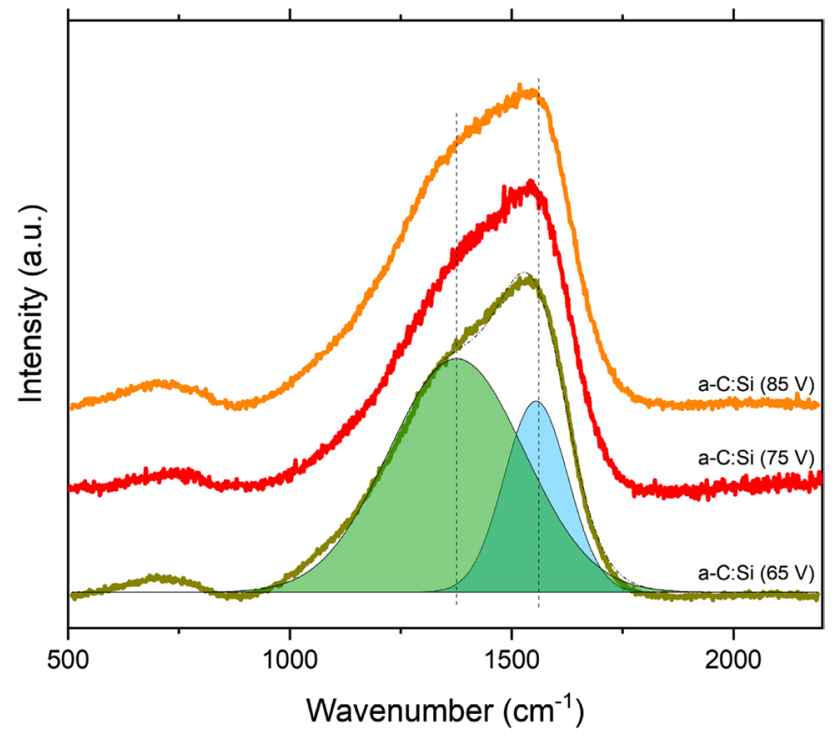

Fig. 1 Raman spectra of the studied carbon films: a-C:Si $(65 \mathrm{~V})$, a-C:Si $(75 \mathrm{~V})$, and a-C:Si (85 V)

was observed to increase with the bias voltage applied during deposition, soaring from $1556 \mathrm{~cm}^{-1}$ in a-C:Si $(65 \mathrm{~V})$ to $1570 \mathrm{~cm}^{-1}$ in a-C:Si $(85 \mathrm{~V})$. This could be aligned with an increase in the residual stresses and defects of the films, as a result of such energetic bombardment [26]. The FWHM (G) has been reported to increase with the disorder of the films, with ordered materials dominated by aromatic rings, such as graphite, having reduced values [33]. Nonetheless, no major changes in the FWHM $(\mathrm{G})$ were observed across the films. Such changes were found in the $I_{\mathrm{D}} / I_{\mathrm{G}}$ ratio, where the D-peak was observed to extend its presence [11]. This effect was likely induced by increasing bias voltage modifications that transformed the existing aromatic bonds into olefinic bonds, leading to the observed decrease in the $I_{\mathrm{D}} / I_{\mathrm{G}}$ ratio $[34,35]$. The film with the lower bias, a-C:Si $(65 \mathrm{~V})$, presented a value of 1.4 that was found to continuously decrease until a value of 1.12 for a-C:Si $(85 \mathrm{~V})$.

\subsection{X-ray photoelectron spectroscopy}

X-ray photoelectron spectroscopy (XPS) was employed to obtain further information on the bonding states through the measurement of both $\mathrm{C} 1 s$ and Si $2 p$ orbitals. These films were observed to present similar doping levels, [Si] $=1.4 \pm 0.2$ at. $\%$, while the $[\mathrm{Ar}]$ increased slightly from a-C:Si $(65 \mathrm{~V}), 3.65$ at. \%, to a-C:Si $(85 \mathrm{~V}), 3.85$ at. \%, allegedly due to the intense bombardment $[36,37]$. The C $1 s$ spectrum was decomposed into four main features: carbon $\mathrm{sp}^{2}$ contribution, carbon $\mathrm{sp}^{3}$ contribution, silicon carbide, and residual surface contaminants (Fig. 2). The $\mathrm{sp}^{2}$-bonded carbon was centred at $284.3 \mathrm{eV}$, while the $\mathrm{sp}^{3}$-bonded carbon was fixed at a separation of 0.95 $\mathrm{eV}$, following prior results in carbon films without hydrogenated precursors [38-40]. The film with the lower bias voltage, a-C:Si $(65 \mathrm{~V})$, presented a $\mathrm{C}-\mathrm{C} / \mathrm{C}-\mathrm{H}$ content of $21.9 \pm 0.6$, value that was found to progressively increase until the value of a-C:Si $(85 \mathrm{~V}), 23.1 \pm 0.4$. Such a trend confirmed a slight change in the coating configuration, as observed previously using Raman spectroscopy. The silicon-carbon bond was found at $283.5 \mathrm{eV}$, and its relative area was also found to present a correlation with bias voltage. This content ranged from $1.1 \%$ in a-C:Si $(65 \mathrm{~V})$ to 2.5 $\%$ in a-C:Si $(85 \mathrm{~V})$, as presented in Fig. 3. Similar results were observed for $\mathrm{Cr}$-doped films with an increase in the relative area of $\mathrm{Cr}-\mathrm{C}$, as the bias voltage was increased [25]. Additionally, surface contaminants in the form of both ether and carbonyl groups $(\mathrm{C}-\mathrm{O}, \mathrm{C}=\mathrm{O})$ were found at 286 and $288 \mathrm{eV}$, respectively.

The Si $2 p$ orbital, of the films under study, displayed changes as a result of the increasing bias voltage employed during deposition (Fig. 3). The Si $2 p$ orbital was deconvoluted into three well-defined doublets, with their maxima in the $2 p_{3 / 2}$ component, corresponding with the existing silicon bonds within the surface of the films. The major doublet in a-C: $\mathrm{Si}(65 \mathrm{~V})$ represented $\mathrm{Si}-\mathrm{O}-\mathrm{C}$ and was centred at $101.6 \mathrm{eV}$. Such a peak has previously been observed to decrease with increasing silicon content [31], although a similar effect was observed in this work as a result of increasing bias voltage. This species has been attributed positive effects on the friction of the films, resulting in a coefficient of friction reductions [41]. Its reduction with bias voltage could therefore play a role in the tribological properties of the films. At the same time, the relative fraction of $\mathrm{Si}-\mathrm{C}$, centred at $100.5 \mathrm{eV}$, and $\mathrm{SiO}_{\mathrm{x}}$, centred at $103.4 \mathrm{eV}$, soared with the former growing from $3.5 \%$ in a-C:Si $(65 \mathrm{~V})$ to $10.2 \%$ in the a-C:Si $(75 \mathrm{~V})$ and $52 \%$ in a-C:Si $(85 \mathrm{~V})$.

Table 1 Silicon content of each of the films as well as Raman parameters extracted after fitting of the spectra, $\mathrm{sp}^{3}$ fraction obtained from XPS, and mechanical properties

\begin{tabular}{llllllll}
\hline & Si content (at. \%) & G-peak $\left(\mathrm{cm}^{-1}\right)$ & FWHM $\left(\mathrm{cm}^{-1}\right)$ & $I_{\mathrm{D}} / I_{\mathrm{G}}$ & $\mathrm{sp}^{3} \mathrm{C}-\mathrm{C}$ content $(\%)$ & $\mathrm{H}(\mathrm{GPa})$ & $\mathrm{E}{ }^{\prime}(\mathrm{GPa})$ \\
\hline a-C:Si (65 V) & $1.3 \pm 0.1$ & $1556 \pm 1$ & $167 \pm 1$ & $1.4 \pm 0.02$ & $21.9 \pm 0.4$ & $13.6 \pm 1.0$ & $157.7 \pm 15.9$ \\
a-C:Si (75 V) [16, 31] & $1.4 \pm 0.1$ & $1557 \pm 2$ & $169 \pm 2$ & $1.23 \pm 0.10$ & $22.5 \pm 0.8$ & $16.1 \pm 1.0$ & $182.7 \pm 7.0$ \\
a-C:Si (85 V) & $1.5 \pm 0.2$ & $1570 \pm 2$ & $168 \pm 1$ & $1.12 \pm 0.02$ & $23.1 \pm 0.6$ & $27.2 \pm 1.5$ & $243.5 \pm 6.5$ \\
\hline
\end{tabular}




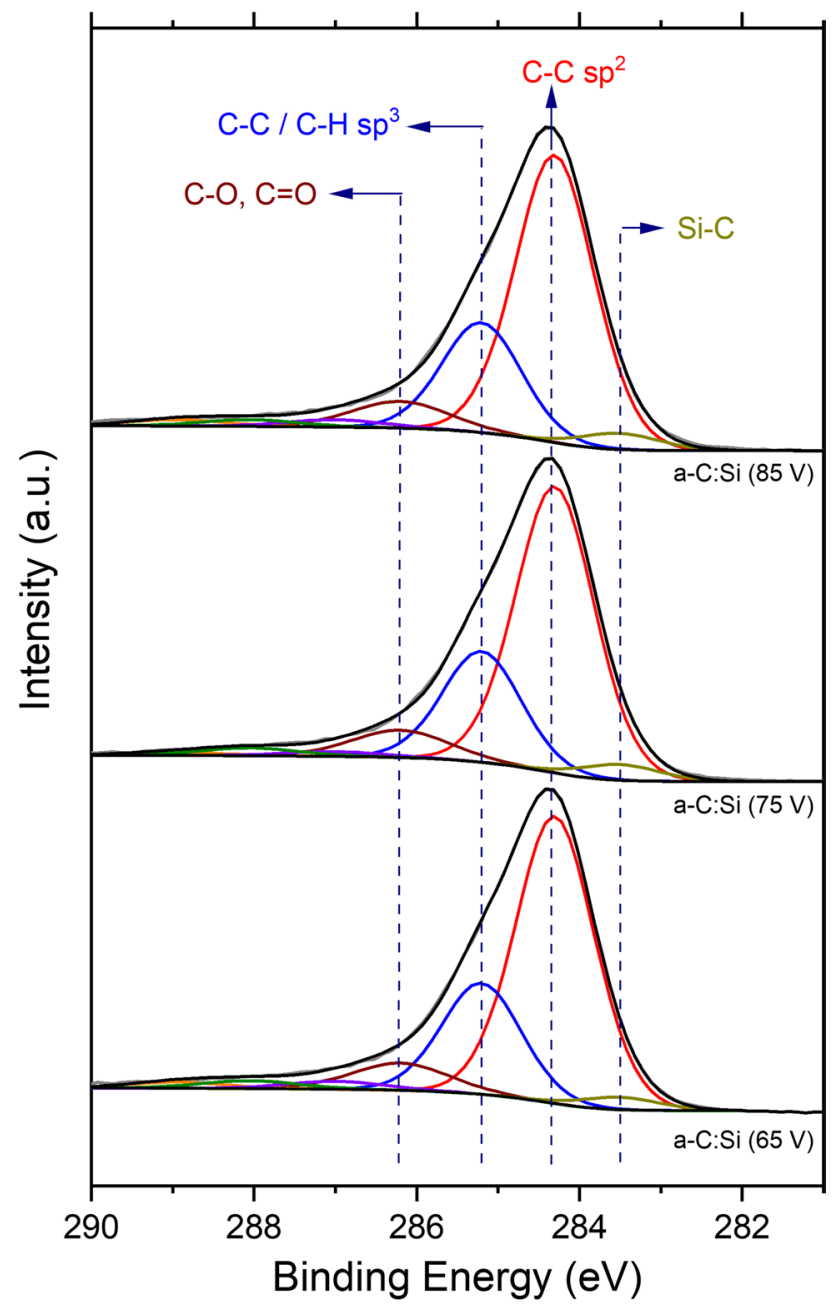

Fig. $2 \mathrm{C} 1 s$ orbital of the films, obtained by XPS, after $1 \mathrm{~h}$ of exposure to $\mathrm{Ar}^{+}$sputtering to remove contaminants

\subsection{Mechanical properties}

The $\mathrm{H}$ and E' of the films were acquired through depthcontrolled indentations, ensuring that the depth remained below a tenth of the total film thickness and limiting any influence from either substrate or surface roughness. The modification of the bias voltage applied to the substrates during deposition had a direct effect on the mechanical properties of the films. As presented in Table 1, both parameters increased from $13.6 \pm 1.0$ and $157.7 \pm 15.9$ respectively in the case of the film with the lover bias voltage applied, a-C:Si $(65 \mathrm{~V})$, to $27.2 \pm 1.5$ and 243.5 \pm 6.5 in the higher bias voltage film, a-C:Si $(85 \mathrm{~V})$. An increase of $\mathrm{H}$ due to the application of larger bias voltages has previously been related to the increase in compressive stress due to the enhanced bombardment of ions [26]. The coating with the lowest depositing bias reported the lowest H/E', usually related to higher plasticity, while a-C:Si

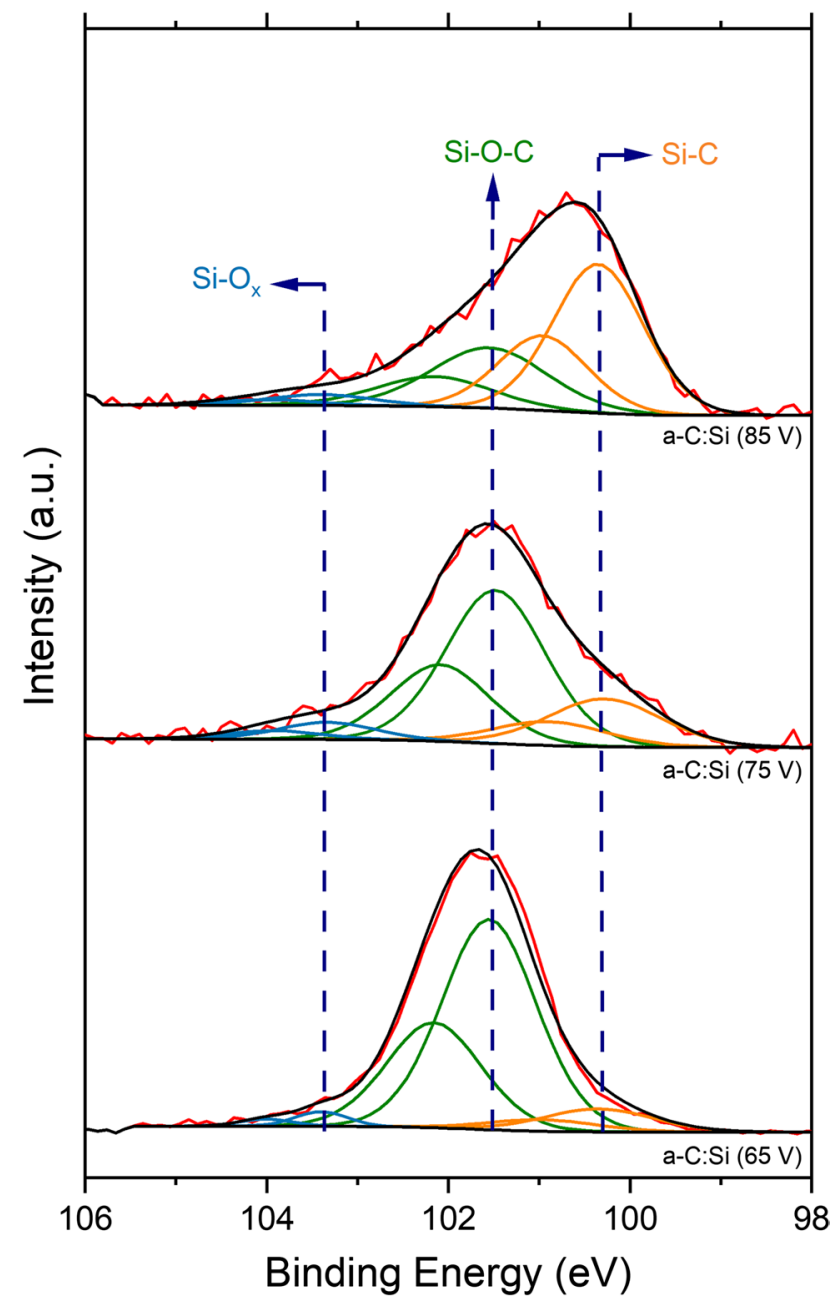

Fig. $3 \mathrm{Si} 2 p$ core-level spectra of the as-deposited Si-doped films obtained by XPS

$(85 \mathrm{~V})$ could display an improved wear resistance due to its higher $\mathrm{H} / \mathrm{E}$ '.

\subsection{Tribological properties}

The tribological performance of the different films was assessed through the testing of the films from room temperature (RT) up to temperatures required for the film to display failure, defined as contact between $\mathrm{Al}_{2} \mathrm{O}_{3}$ counterpart and the steel substrate. The friction curves for each condition and temperature can be found in Fig. 4, while a summary of both the coefficient of friction (COF) and the specific wear rate are presented in Fig. 5. The $\mathrm{sp}^{2}$-configuration modifications, induced by the higher contact temperatures, exhibited at the end of the test are presented in Fig. 6 for a-C:Si $(85 \mathrm{~V})$, where areas inside and outside the wear track were analysed through Raman mapping.

For samples tested at room temperature, relatively high flash temperatures were reached in the contact during the 

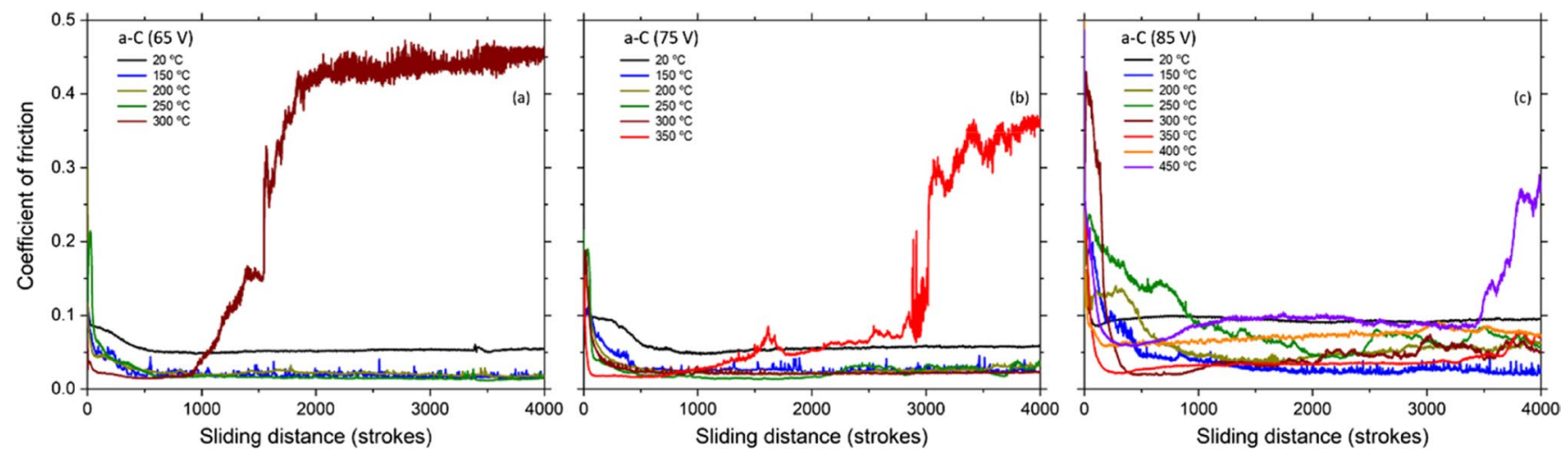

Fig. 4 Evolution of the coefficient of friction with temperature for all tested coatings using a $6.3 \mathrm{~mm}$ diameter $\mathrm{Al}_{2} \mathrm{O}_{3}$ balls as a counterpart, $10 \mathrm{~N}$ load, and $1 \mathrm{~cm} \mathrm{~s}^{-1}$ linear speed for a a-C:Si $(65 \mathrm{~V})$; b a-C:Si (75 V); $\mathbf{c}$ a-C:Si (85 V)
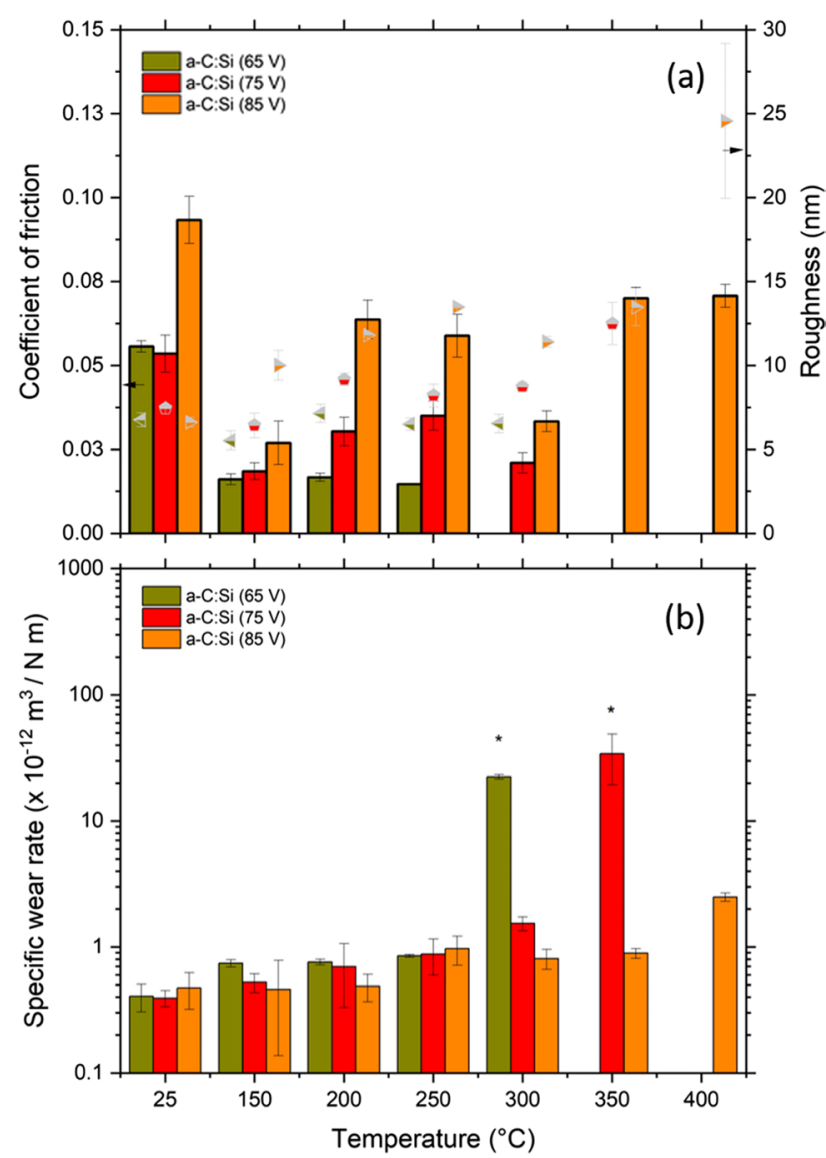

Fig. 5 Summary of the results obtained from ball-on-disk friction tests using $\mathrm{Al}_{2} \mathrm{O}_{3}$ as counterpart. a Averaged steady-state values of the coefficient of friction during the final 1000 strokes, and roughness evolution for each coating. b Specific wear rates obtained after tribological testing

running-in of the films, due to the frictional energy generated $[42,43]$. Once this period was overcome, graphitised transfer layers are expected to be created on the counterpart due to the low shear strength, providing a reduction of such friction and stable friction behaviour [44]. The two films with lower bias voltages, a-C:Si $(65 \mathrm{~V})$ and a-C:Si $(75 \mathrm{~V})$, reported lower COFs than a-C:Si $(85 \mathrm{~V})$, as presented in Figs. 4 and 5. Such difference is thought to be related to the increasing $\mathrm{Si}-\mathrm{C}$ fraction reported earlier, whereby increasing bias voltage changes in the surface chemistry of the film were identified. A reduction in the relative area of $\mathrm{Si}-\mathrm{O}-\mathrm{C}$ within the Si $2 p$ orbital was also observed with increasing bias voltage. The former could have driven the $\mathrm{COF}$ increase observed at this temperature for a-C:Si $(85 \mathrm{~V})$, as it is more abrasive [45], while the reduction in $\mathrm{Si}-\mathrm{O}-\mathrm{C}$ may also affect the tribological properties, since it has been attributed lubricious properties $[19,20]$. The graphitization of the coatings induced by the friction was monitored through the change of $\mathrm{sp}^{2}$-configuration within these films (Fig. 6, Fig. S1, Fig. S2). These maps allowed the study of the condition of the coating inside the wear track at the end of the tribological test. For instance, a-C:Si $(85 \mathrm{~V})$ was found to present a reduction in the G-peak position and a FWHM $(\mathrm{G})$ increase, with no significant changes observed in $I_{\mathrm{D}} / I_{\mathrm{G}}$ (Fig. 6a). Earlier, this has been attributed to a reduction of defects for annealing temperatures below $200{ }^{\circ} \mathrm{C}$ [46], which may indicate that the contact temperature reached at the end of the contact was below such value. A similar trend was observed for a-C:Si (65 V) (see Fig. S1a) although with smaller values characteristic for a film deposited with lower bias voltage. Both in this specimen and a-C:Si (75 V) (Fig. S2a), the presence of a groove within the wear track was identified as a progressive graphitization localized in a line due to abrasive wear. The latter film presented a clearer impact of the temperature-induced graphitization within the wear track than its peers, with both areas clearly differentiated.

At $150{ }^{\circ} \mathrm{C}$, the coefficient of friction presented a twofold decrease (Fig. 4), potentially due to the progressive graphitisation of the transfer layers. The temperature reached at the contact was now compounded by the contact and the environmental temperature [47]. The running-in length was

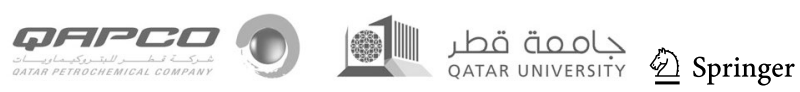




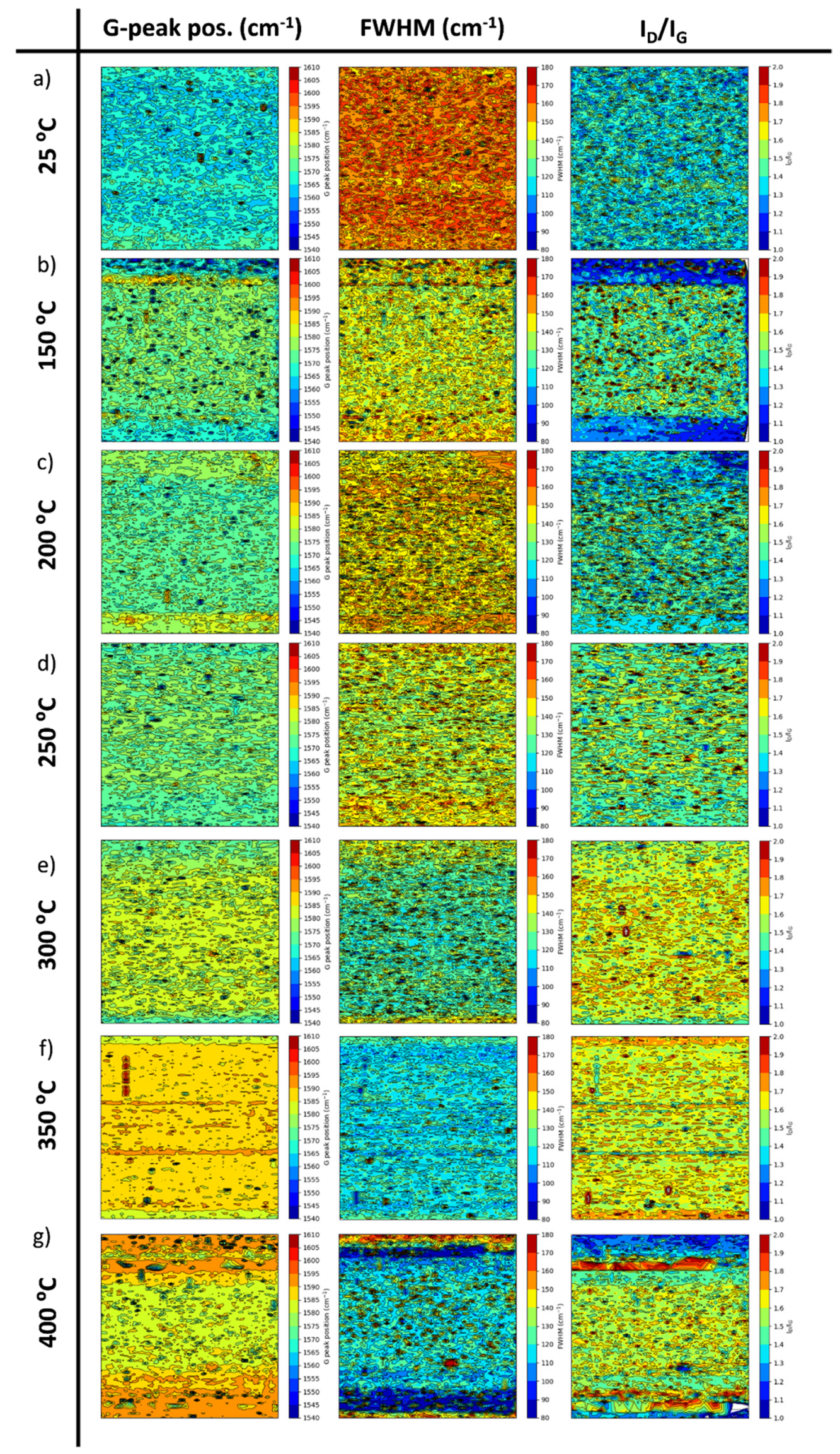

年 Springer 
4Fig. 6 Raman mapping of the wear tracks of a-C:Si $(85 \mathrm{~V})$ at $\mathbf{a} 25^{\circ} \mathrm{C}$, b $150{ }^{\circ} \mathrm{C}$, c $200{ }^{\circ} \mathrm{C}$, d $250{ }^{\circ} \mathrm{C}$, e $300{ }^{\circ} \mathrm{C}$, f $350{ }^{\circ} \mathrm{C}$, and g $400{ }^{\circ} \mathrm{C}$. Note that the wear track length mapped (X-axis) was kept constant at $30 \mu \mathrm{m}$, while the wear track width (Y-axis) was changed to account for the width increase with temperature

found to be directly correlated to the bias voltage employed to deposit the specimens for all temperatures. The mapping at this temperature reported an extended graphitisation inside the wear track (Fig. 6b). The specimens were found to present a progressive transition from olefinic to aromatic bonding which was found to be induced by the contact temperatures reached. This was probed through the G-peak position displacements towards the red, FWHM (G) reductions, and the $I_{\mathrm{D}} / I_{\mathrm{G}}$ ratio increase confirming the rise of the $\mathrm{D}$ peak. The changes in the Raman parameters observed within the wear track at RT were now found in the areas outside the wear track. The film deposited with the lower bias voltage, a-C:Si (65 V), was severely affected (Fig. S1), while a-C:Si $(75 \mathrm{~V})$ reported intermediate values to a-C:Si $(65 \mathrm{~V})$ and a-C:Si (85 V), as observed in Fig. S2., which correlates with the impact of bias voltage on the thermal stability mentioned earlier. The changes in the Raman parameters observed within the wear track at RT were now found in the areas outside the wear track.

As the temperature was increased, a-C $(65 \mathrm{~V})$ and a-C (75 V) were found to have a stable COF. At $200{ }^{\circ} \mathrm{C}$, a-C:Si $(65 \mathrm{~V})$ presented extended changes within the wear track with an accelerated graphitisation within the wear track that kept progressing, while a-C:Si $(75 \mathrm{~V})$ and a-C:Si $(85 \mathrm{~V})$ presented limited changes with the lower temperature. At $250{ }^{\circ} \mathrm{C}$, the wear track in a-C:Si $(65 \mathrm{~V})$ seemed to have reached stage 1 defined by Ferrari et al. [11]. This was clearly observed in the graphitisation trajectory of FWHM (G) and G-peak position, which decreased from 115 to 100 $\mathrm{cm}^{-1}$ and increased from 1580 to $1585 \mathrm{~cm}^{-1}$ respectively, between 200 and $250{ }^{\circ} \mathrm{C}$. Additionally, the $I_{\mathrm{D}} / I_{\mathrm{G}}$ ratio displayed an increasing trend from RT up to $200{ }^{\circ} \mathrm{C}$, where it changed and dropped from 1.7 to 1.5 at $250{ }^{\circ} \mathrm{C}$. Nevertheless, the transition started in the areas outside the wear track at $200{ }^{\circ} \mathrm{C}$, as can be seen in Fig. S1c. This is significant, as it confirmed that the coating presents different graphitised states throughout its thickness. Additionally, it also confirmed that the frictional heat generated during the contact was superficial, due to the linear speed, as the coating exposed inside the wear track was not as graphitised as that outside. Similarly, a-C:Si $(75 \mathrm{~V})$ presented the same trend, although due to the higher thermal stability, the film had a lower ordering trend, which delayed such behaviour by $50{ }^{\circ} \mathrm{C}$ until $300{ }^{\circ} \mathrm{C}$ (Fig. S2e). These coatings reached their failure at $300{ }^{\circ} \mathrm{C}$ and $350{ }^{\circ} \mathrm{C}$, respectively. At such temperatures, the films were found to display a minimal running-in due to the minimised shear strength $[14,48]$. Meanwhile, their SWR progressively increased with temperature, which is associated with the largest graphitization expected within the wear tracks with increasing temperature. The lowest bias voltage specimen, a-C $(65 \mathrm{~V})$, presented larger SWR than any of the other coatings under most temperatures. This can be attributed to its initial state, which was already more graphitized, and would have underpinned a lower COF. This also caused its failure at lower temperatures than its peers.

The film with the highest bias voltage, a-C:Si $(85 \mathrm{~V})$, was found to present larger signs of graphitisation within the wear track as the annealing temperature was increased. This led to an increasing $I_{\mathrm{D}} / I_{\mathrm{G}}$ inside the wear track, accompanied by an increase in COF up to $300{ }^{\circ} \mathrm{C}$, when the wear track almost reached complete graphitisation. Similar trends were observed with the G-peak position and the FWHM $(\mathrm{G})$, which continued their accelerated aromatic transition within the wear track, induced by the additional frictional energy generated at the contact. This led to $I_{\mathrm{D}} / I_{\mathrm{G}}$ values of 1.8 inside the wear track, while outside they remained at 1.6.

At the end of the $350{ }^{\circ} \mathrm{C}$ test, a-C:Si $(85 \mathrm{~V})$ presented G-peak positions of $1590 \mathrm{~cm}^{-1}$ and $1580 \mathrm{~cm}^{-1}$, and FWHM (G) of $110 \mathrm{~cm}^{-1}$ and $120 \mathrm{~cm}^{-1}$, inside and outside the wear track respectively, which confirmed the accelerated amorphization trajectory within the track [11]. Meanwhile, the $I_{\mathrm{D}} / I_{\mathrm{G}}$ analysis presented larger values outside the wear track than inside, but still higher than those observed at $300{ }^{\circ} \mathrm{C}$. This indicated that the coating surface was close to a transition into stage 1 from the amorphization trajectory defined by Ferrari et al. [11]. As mentioned earlier, the temperature reached inside the wear track was significantly higher than the annealing, but $I_{\mathrm{D}} / I_{\mathrm{G}}$ was below one expected at this temperature. It is thought that it was caused by the lower shear strength of the films in stage 1 , which allowed the removal of the graphitised part of the coating shortly after reaching such state. This could be confirmed by the groove observed in the same figure, caused by material entrapment, which is in the frontier with stage 1 , and found in the wear track solely due to its larger depth (Fig. 6f). It was also confirmed that the film displayed a heterogeneous outcome of the annealing. The inner coating was less ordered than the superficial film, and the flash temperatures that originated during the friction test were limited to the surface due to the relatively large tribological velocity [47]. This was also observed at $400{ }^{\circ} \mathrm{C}$, where the area outside the track completely transitioned into stage 1 , with drops in FWHM $(\mathrm{G})$ and $I_{\mathrm{D}} / I_{\mathrm{G}}$ beyond those found in the areas inside the track (Fig. $6 \mathrm{~g}$ ). Simultaneously, the G-peak position also increased beyond those values found inside the track. This could assist in the relatively more stable COF found at $350{ }^{\circ} \mathrm{C}$ and $400{ }^{\circ} \mathrm{C}$, due to the formation of transfer layers with increased stability. The coating was found to fail at $450{ }^{\circ} \mathrm{C}$, as it reached complete graphitization at the end of the $400{ }^{\circ} \mathrm{C}$ test. Nevertheless, a-C:Si $(85 \mathrm{~V})$ increased the operative window by

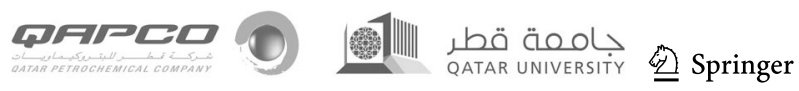


$100{ }^{\circ} \mathrm{C}$ from that of a-C:Si $(75 \mathrm{~V})$, and $150{ }^{\circ} \mathrm{C}$ from that of a-C:Si $(65 \mathrm{~V})$.

\subsection{High-temperature integrity of the coatings}

Cross-sections of the coatings outside the wear track after their tribological test at $300{ }^{\circ} \mathrm{C}$ were studied by TEM using a high-angle annular dark-field detector (HAADF).

Figure 7 shows the cross-section with the coating sandwiched between a protective Pt layer on the top and the $\mathrm{Cr}-\mathrm{C}$ inner layer at the bottom, along the EDS analysis of the coatings. These films have been previously reported to display the diffusion of oxygen from the top layer, dark features in Fig. 7, with their ingress point at the joints of the cauliflower-like structures, characteristic for the surface of these films, indicated by A in Fig. 7a [49]. These features were reported to diffuse deeper with increasing temperature, which impacted their adhesion and tribological behaviour, although increasing Si-doping was reported to minimise the depth of such features [31].

It is believed that oxygen diffusion is linked to the low density of the films. As shown in Fig. 7a, both in the HAADF and EDS figures, the dark features reached the interlayer of a-C: $\mathrm{Si}(65 \mathrm{~V})$ at $300{ }^{\circ} \mathrm{C}$, concurrently with its tribological failure. These features covered the entire coating and were found to form oxides in the interlayer, dark features identified as B. Figure $7 \mathrm{~b}$ shows a-C:Si $(75 \mathrm{~V})$ at the same temperature, while a-C:Si $(85 \mathrm{~V})$ displays a reduction in the penetration depth (Fig. 7c). Diamond-like carbon coatings deposited with increasing bias voltages have been often associated with larger densities [12], which could be aiding to minimise the oxygen diffusion. These depositions could also render larger $\mathrm{sp}^{3}$ fractions, but that is not believed to be driving the different performance at high temperatures, as were found to remain within error, as presented in Table 1 .

\section{Conclusions}

Si-doped DLC coatings deposited with increasing bias voltages ranging from 65 to $85 \mathrm{~V}$ have been studied. The film structure was found to become olefinic with increasing bias voltage, which agreed with an increase in the $\mathrm{sp}^{3}$ carbon content from $21.9 \pm 0.4$ in a-C $(65 \mathrm{~V})$ to $23.1 \pm 0.6$ in a-C $(85 \mathrm{~V})$. Simultaneously, the hardness doubled from $13.6 \pm$ 1.0 to $27.2 \pm 1.5 \mathrm{GPa}$ in the same coatings.

The film deposited with the largest bias voltage, a-C (85 $\mathrm{V})$, was found to have the highest thermal stability of the films, increasing by $100^{\circ} \mathrm{C}$ that of a-C $(75 \mathrm{~V})$, and by 150 ${ }^{\circ} \mathrm{C}$ that of a-C $(65 \mathrm{~V})$. The tribological performance was found to be also affected by the bias voltage, with the softest coating, a-C $(65 \mathrm{~V})$ reporting consistently the lowest COF, although not the lowest specific wear rate.

An alternative approach for the $\mathrm{sp}^{2}$ configuration evaluation of the coatings at the end of the tribological contact was provided. This methodology experimentally confirmed the coating does not present a homogeneous behaviour during annealing. Additionally, it was experimentally measured that the flash temperatures reached inside the contact were superficial and only affected those layers in contact. It is thought that this technique could be developed further and employed to experimentally estimate the final contact temperature reached within the wear track through the understanding of the coating changes with temperature.

Supplementary Information The online version contains supplementary material available at https://doi.org/10.1007/s42247-021-00263-w.
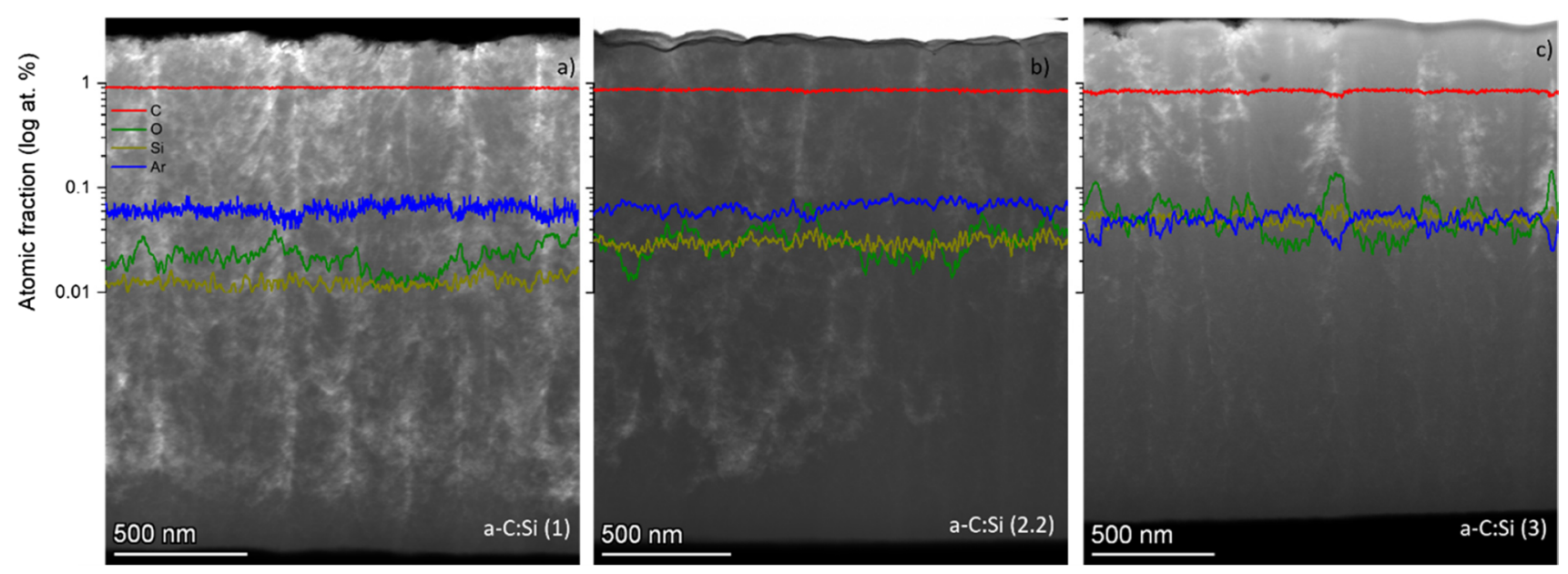

Fig. 7 TEM image of a a-C:Si (85 V), b a-C:Si (75 V) [31], and c a-C:Si (85 V) after tribological testing at $300{ }^{\circ} \mathrm{C}$. TEM foils were extracted from pristine regions outside the wear track 
Acknowledgements We would like to acknowledge the University of Warwick's Spectroscopy Research Technology Platform (RTP), Dr. Ben Breeze. The authors are grateful to Ms. Susan Field and Dr. Raul Chinchilla for the fruitful discussions.

Funding This study is financially supported by the Engineering and Physical Science Research Council (EPRSC) supported this work through the Centre for Doctoral Training in Diamond Science and Technology (EP/L015315/1).

\section{Declarations}

Statement of originality The authors confirm the following:

- This work was done wholly by the cited authors.

- Where published work was consulted, it was clearly attributed, and the source was always provided.

- This work has not been published by another journal and to the best of our knowledge is original work.

Conflict of interest The authors declare no competing interests.

Open Access This article is licensed under a Creative Commons Attribution 4.0 International License, which permits use, sharing, adaptation, distribution and reproduction in any medium or format, as long as you give appropriate credit to the original author(s) and the source, provide a link to the Creative Commons licence, and indicate if changes were made. The images or other third party material in this article are included in the article's Creative Commons licence, unless indicated otherwise in a credit line to the material. If material is not included in the article's Creative Commons licence and your intended use is not permitted by statutory regulation or exceeds the permitted use, you will need to obtain permission directly from the copyright holder. To view a copy of this licence, visit http://creativecommons.org/licenses/by/4.0/.

\section{References}

1. Erdemir A, Donnet C. Tribology of diamond-like carbon films: recent progress and future prospects. J. Phys. D Appl. Phys. 39, (2006). https://doi.org/10.1088/0022-3727/39/18/R01.

2. F. Mangolini, B.A. Krick, T.D.B. Jacobs, S.R. Khanal, F. Streller, J.B. McClimon et al., Effect of silicon and oxygen dopants on the stability of hydrogenated amorphous carbon under harsh environmental conditions. Carbon N Y 130, 127-136 (2018). https://doi. org/10.1016/j.carbon.2017.12.096

3. S. Bhowmick, A.T. Alpas, The role of diamond-like carbon coated drills on minimum quantity lubrication drilling of magnesium alloys. Surf. Coatings Technol. 205, 5302-11 (2011). https://doi. org/10.1016/j.surfcoat.2011.05.037

4. A. Suzuki, Y. Aiyama, M. Tokoro, H. Sekiguchi, M. Masuko, Friction and wear characteristics of hydrogenated diamond-like carbon films formed on the roughened stainless steel surface. Wear 269, 118-124 (2010). https://doi.org/10.1016/j.wear.2010.03.013

5. K. Holmberg, A. Matthews, Coatings Tribology, (2009) https:// doi.org/10.1016/S0301-679X(98)00013-9

6. C. Donnet, A. Erdemir, Tribology of diamond-like carbon films: fundamentals and applications. (2008). https://doi.org/10.1007/ 978-0-387-49891-1

7. H. Ronkainen, K. Holmberg, Environmental and thermal effects on the tribological performance of DLC coatings. Tribology of Diamond-Like Carbon Films 155-200. (2008) https://doi.org/10. 1007/978-0-387-49891-1_6
8. X. Deng, H. Kousaka, T. Tokoroyama, N. Umehara, Thermal stability and high-temperature tribological properties of a-C: $\mathrm{H}$ and Si-DLC deposited by microwave sheath voltage combination plasma. Tribol. Online 8, 257-264 (2013). https://doi.org/ 10.2474/trol.8.257

9. K.D. Koshigan, F. Mangolini, J.B. Mcclimon, B. Vacher, S. Bec, R.W. Carpick et al., Understanding the hydrogen and oxygen gas pressure dependence of the tribological properties of silicon oxide-doped hydrogenated amorphous carbon coatings. Carbon N. Y. 93, 851-860 (2015). https://doi.org/10.1016/j.carbon.2015. 06.004

10. D. Sheeja, B.K. Tay, S.P. Lau, X. Shi, Tribological properties and adhesive strength of DLC coatings prepared under different substrate bias voltages. Wear 249, 433-439 (2001). https://doi. org/10.1016/S0043-1648(01)00541-5

11. A.C. Ferrari, J. Robertson, Interpretation of Raman spectra of disordered and amorphous carbon. Phys. Rev. B 61, 1409514107 (2000). https://doi.org/10.1103/PhysRevB.61.14095

12. C. Casiraghi, F. Piazza, A.C. Ferrari, D. Grambole, J. Robertson, Bonding in hydrogenated diamond-like carbon by Raman spectroscopy. Diam. Relat. Mater. 14, 1098-1102 (2005). https://doi.org/10.1016/j.diamond.2004.10.030

13. W.J. Yang, Y.H. Choa, T. Sekino, K.B. Shim, K. Niihara, K.H. Auh, Thermal stability evaluation of diamond-like nanocomposite coatings. Thin. Solid Films 434, 49-54 (2003). https:// doi.org/10.1016/S0040-6090(03)00466-8

14. Y. Liu, A. Erdemir, E.I. Meletis, An investigation of the relationship between graphitization and frictional behavior of DLC coatings. Surf. Coatings Technol. 86-87, 564-568 (1996). https://doi.org/10.1016/S0257-8972(96)03057-5

15. Santiago JA, Fernández-Martínez I, Sánchez-López JC, T.C. Rojas, Wennberg A, Bellido-González V, et al. Tribomechanical properties of hard Cr-doped DLC coatings deposited by low-frequency HiPIMS. Surf. Coatings Technol. 382, 124899. https://doi.org/10.1016/j.surfcoat.2019.124899

16. B.J. Rodriguez, T.L. Schiller, D. Proprentner, M. Walker, C.T.J. Low, B. Shollock et al., Effect of chromium doping on high temperature tribological properties of silicon-doped diamondlike carbon films. Tribol. Int. 152, 106546 (2020). https://doi. org/10.1016/j.triboint.2020.106546

17. H. Ronkainen, S. Varjus, J. Koskinen, K. Holmberg, Differentiating the tribological performance of hydrogenated and hydrogen-free DLC coatings. Wear 249, 260-266 (2001). https://doi. org/10.1016/S0043-1648(01)00558-0

18. H. Ronkainen, J. Koskinen, J. Likonen, S. Varjus, J. Vihersalo, Characterization of wear surfaces in dry sliding of steel and alumina on hydrogenated and hydrogen-free carbon films $\mathbf{3}$, 1329-1336 (1994)

19. O. Jantschner, S.K. Field, D. Music, V.L. Terziyska, J.M. Schneider, F. Munnik et al., Sputtered Si-containing low-friction carbon coatings for elevated temperatures. Tribol. Int. 77, 15-23 (2014). https://doi.org/10.1016/j.triboint.2014.04.006

20. O. Jantschner, S.K. Field, D. Holec, A. Fian, D. Music, J.M. Schneider et al., Origin of temperature-induced low friction of sputtered Si-containing amorphous carbon coatings. Acta Mater. 82, 437-446 (2015). https://doi.org/10.1016/j.actamat. 2014.09.030

21. R. Gilmore, R. Hauert, Comparative study of the tribological moisture sensitivity of Si-free and Si-containing diamond-like carbon films. Surf Coatings Technol. 133, 437-442 (2000). https:// doi.org/10.1016/S0257-8972(00)00927-0

22. S.E. Ong, S. Zhang, H. Du, D. Sun, Relationship between bonding structure and mechanical properties of amorphous carbon containing silicon. Diam. Relat. Mater. 16, 1628-1635 (2007). https://doi. org/10.1016/j.diamond.2007.02.009 
23. S. Domínguez-Meister, T.C. Rojas, J.E. Frías, J.C. SánchezLópez, Silver effect on the tribological and antibacterial properties of a-C: Ag coatings. Tribol. Int. 140, 1-11 (2019). https://doi.org/ 10.1016/j.triboint.2019.06.030

24. G.F. Zhang, X. Zheng, L.J. Guo, Z.T. Liu, N.K. Xiu, Influence of deposition parameters on the refractive index and growth rate of diamond-like carbon films. Surf. Coatings Technol. 64, 127-130 (1994). https://doi.org/10.1016/S0257-8972(09)90013-5

25. W. Dai, H. Zheng, G. Wu, A. Wang, Effect of bias voltage on growth property of Cr-DLC film prepared by linear ion beam deposition technique. Vacuum 85, 231-235 (2010). https://doi. org/10.1016/j.vacuum.2010.06.001

26. C. Saringer, C. Oberroither, K. Zorn, R. Franz, C. Mitterer, Influence of discharge power and bias potential on microstructure and hardness of sputtered amorphous carbon coatings. J. Vac. Sci. Technol. A Vacuum, Surfaces, Film 36, 021501 (2018). https:// doi.org/10.1116/1.5001141

27. X.L. Zhou, S. Tunmee, T. Suzuki, P. Phothongkam, K. Kanda, K. Komatsu et al., Quantitative NEXAFS and solid-state NMR studies of $\mathrm{sp} 3 /(\mathrm{sp} 2+\mathrm{sp} 3)$ ratio in the hydrogenated DLC films. Diam. Relat. Mater. 73, 232-240 (2017). https://doi.org/10.1016/j. diamond.2016.09.026

28. J.R. Shi, X. Shi, Z. Sun, S.P. Lau, B.K. Tay, H.S. Tan, Resonant Raman studies of tetrahedral amorphous carbon films. Diam. Relat. Mater. 10, 76-81 (2001). https://doi.org/10.1016/S09259635(00)00403-9

29. M. Chhowalla, J. Robertson, C.W. Chen, S.R.P. Silva, C.A. Davis, G.A.J. Amaratunga et al., Influence of ion energy and substrate temperature on the optical and electronic properties of tetrahedral amorphous carbon (ta-C) films. J. Appl. Phys. 81, 139-145 (1997). https://doi.org/10.1063/1.364000

30. Y. Pauleau, Residual stresses in physically vapor-deposited thin films. vol. 1. (2002). https://doi.org/10.1016/B978-012512908-4/ 50012-6.

31. D.A. Shirley, High-resolution x-ray photoemission spectrum of the valence bands of gold. Phys. Rev. B 5, 4709-4714 (1972). https://doi.org/10.1103/PhysRevB.5.4709

32. J. Robertson, E. O'Reilly, Electronic and atomic structure of amorphous carbon. Phys. Rev. B 35, 2946-2957 (1987). https:// doi.org/10.1103/PhysRevB.35.2946

33. J. Robertson, Diamond-like amorphous carbon. Mater. Sci. Eng. 37, 129-281 (2002). https://doi.org/10.1016/S0927-796X(02) 00005-0

34. J.F. Zhao, P. Lemoine, Z.H. Liu, J.P. Quinn, J.A. McLaughlin, Effects of $\mathrm{Si}$ incorporation on the microstructure and nanomechanical properties of DLC thin films. J. Phys. Condens. Matter. 12, 9201-9213 (2000). https://doi.org/10.1088/0953-8984/12/44/ 302

35. J. Hilbert, F. Mangolini, J.B. McClimon, J.R. Lukes, R.W. Carpick, Si doping enhances the thermal stability of diamond-like carbon through reductions in carbon-carbon bond length disorder. Carbon N. Y. 131, 72-78 (2018). https://doi.org/10.1016/j.carbon. 2018.01.081
36. H. Oettel, R. Wiedemann, Residual stresses in PVD hard coatings. Surf. Coat. Technol. 76-77, 265-273 (1995). https://doi.org/10. 1016/0257-8972(95)02581-2

37. J.J. Cuomo, R.J. Gambino, Incorporation of rare gases in sputtered amorphous metal films. Am. Vac. Soc. 152, 152-157 (2014). https://doi.org/10.1116/1.569109

38. J. Díaz, G. Paolicelli, S. Ferrer, F. Comin, Separation of the sp3 and $\mathrm{sp} 2$ components in the $\mathrm{C} 1 \mathrm{~s}$ photoemission spectra of amorphous carbon films. Phys. Rev. B 54, 8064-8069 (1996). https:// doi.org/10.1103/PhysRevB.54.8064

39. W. Möller, Modeling of the sp3/sp2 ratio in ion beam and plasmadeposited carbon films. Appl. Phys. Lett 59, 2391-2393 (1991). https://doi.org/10.1063/1.106026

40. P. Mérel, M. Tabbal, M. Chaker, S. Moisa, J. Margot, Direct evaluation of the sp 3 content in diamond-like-carbon films by XPS. Appl. Surf. Sci. 136, 105-110 (1998). https://doi.org/10.1016/ S0169-4332(98)00319-5

41. M. Evaristo, R. Azevedo, C. Palacio, A. Cavaleiro, Influence of the silicon and oxygen content on the properties of non-hydrogenated amorphous carbon coatings. Diam. Relat. Mater. 70, 201-210 (2016). https://doi.org/10.1016/j.diamond.2016.10.024

42. D.W. Kim, K.W. Kim, Effects of sliding velocity and normal load on friction and wear characteristics of multi-layered diamond-like carbon (DLC) coating prepared by reactive sputtering. Wear 297, 722-730 (2013). https://doi.org/10.1016/j.wear.2012.10.009

43. Z.F. Zhou, K.Y. Li, I. Bello, C.S. Lee, S.T. Lee, Study of tribological performance of ECR-CVD diamond-like carbon coatings on steel substrates Part 2 The analysis of wear mechanism. . Wear 258, 1589-1599 (2005). https://doi.org/10.1016/j.wear.2004.10. 005

44. A. Erdemir, C. Bindal, J. Pagan, P. Wilbur, Characterization of transfer layers on steel surfaces sliding against diamond-like hydrocarbon films in dry nitrogen. Surf. Coatings Technol. 76-77, 559-563 (1995). https://doi.org/10.1016/0257-8972(95)02518-9

45. A. Blomberg, M. Olsson, S. Hogmark, Wear mechanisms and tribo mapping of $\mathrm{Al} 2 \mathrm{O} 3$ and $\mathrm{SiC}$ in dry sliding. Wear 171, 77-89 (1994). https://doi.org/10.1016/0043-1648(94)90350-6

46. N.M.J. Conway, A.C. Ferrari, A.J. Flewitt, J. Robertson, W.I. Milne, A. Tagliaferro et al., Defect and disorder reduction by annealing in hydrogenated tetrahedral amorphous carbon. Diam. Relat. Mater. 9, 765-770 (2000). https://doi.org/10.1016/S09259635(99)00271-X

47. Stachowiak GW, Batchelor AW. Engineering tribology. 1993.

48. Y. Liu, A. Erdemir, E.I. Meletis, A study of the wear mechanism of diamond-like carbon films. Surf. Coatings. Technol. 82, 48-56 (1996). https://doi.org/10.1016/0257-8972(95)02623-1

49. Q. Wang, F. Zhou, X. Ding, Z. Zhou, C. Wang, W. Zhang et al., Structure and water-lubricated tribological properties of Cr/a$\mathrm{C}$ coatings with different $\mathrm{Cr}$ contents. Tribol. Int. 67, 104-115 (2013). https://doi.org/10.1016/j.triboint.2013.07.002 